${ }^{\circledR}$ Entomologica Fennica. 5 December 1995

\title{
Seasonal occurrence of arthropods as a source of food for birds in Finnish Lapland
}

\author{
Simo Veistola, Tapio Eeva \& Esa Lehikoinen
}

Veistola, S., Eeva, T. \& Lehikoinen, E. 1995: Seasonal occurrence of arthropods as a source of food for birds in Finnish Lapland. - Entomol. Fennica $6: 177-181$.

The seasonal occurrence in arthropod abundance was studied in Utsjoki, northernmost Finland, from the viewpoint that arthropods form an important food resource for birds. On ground surfaces, Araneae was the most abundant taxon. The abundance peak of spiders occurred in June. Diptera, which was the dominant taxon in samples collected from dwarf shrubs, had their dominance peak in July. In birch foliage, Homoptera and Coleoptera were most common in June, but lepidopteran and symphytan larvae dominated in late summer. The larvae in pines (Symphyta; Diprionidae and Pamphiliidae) also had their abundance peak in autumn. The role of predation in the seasonality is discussed from the point-of-view of both birds and arthropods.

Simo Veistola, Tapio Eeva \& Esa Lehikoinen, Laboratory of Ecological Zoology, Department of Biology, University of Turku, FIN-20500 Turku, Finland

\section{Introduction}

The annual fluctuation of arthropods may have strong effects on their host plants, prey and predators (e.g. Krebs 1985). To understand the relationships between organisms, we need studies of the fluctuation of arthropod groups, not only the fluctuation of some species (Wolda 1988). We are interested in the seasonal variation of arthropod density, as they constitute the main food of insectivorous birds. In this paper, we present findings on seasonal variation in the abundance of arthropods grouped in a way which might be relevant to the foraging habits of birds. Our results show the general trends of how the abundance of herbivorous and predatory arthropods fluctuates seasonally in the northern forests. Against this background, we briefly discuss the consequences of seasonal variation for both interacting sides.

\section{Material and methods}

The study area lies at the northern forest limit dominated by mountain birch (Betula pubescens ssp. tortuosa) and Scots pine (Pinus sylvestris) in the valleys of the Kevojoki and Utsjoki rivers. Details of the vegetation of the study area have been presented by Kallio et al. (1969).

The arthropod abundance on the ground and field layers and in the foliage of dwarf shrubs and trees was studied using pitfall traps, sweepnetting, the tree-knocking method and frass-collectors. The study sites were situated near the Kevo Subarctic Research Institute $\left(69^{\circ} 45^{\prime} \mathrm{N}\right.$, $27^{\circ} 01^{\prime} \mathrm{E}$ ), but three tree-knocking sites were 10 $20 \mathrm{~km}$ away from the station. The detailed locations of the study sites have been presented by Eeva (1989).

We had eight pitfall traps (diameter $4.2 \mathrm{~cm}$ ) 

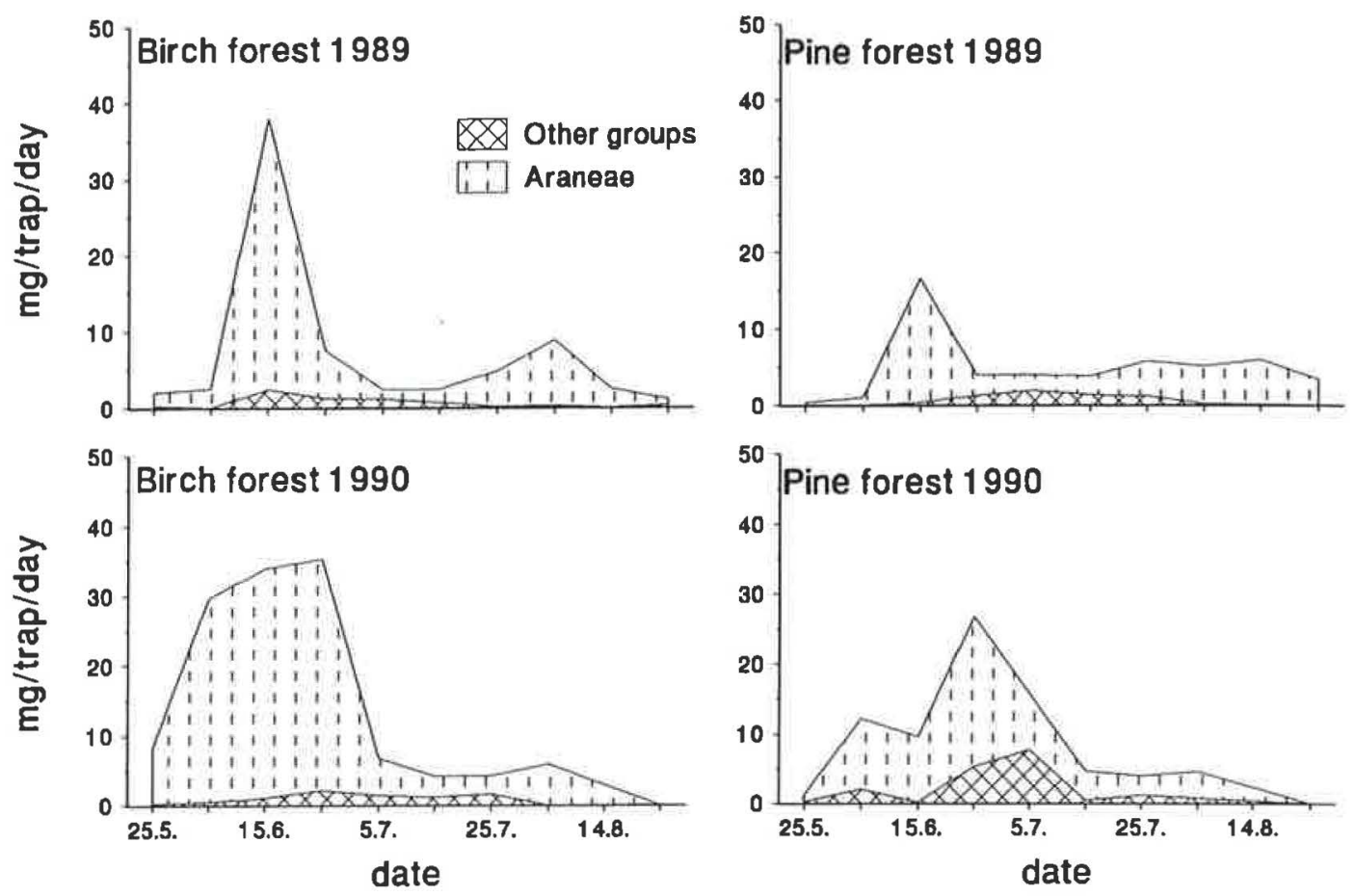

Fig. 1. Seasonal variation of arthropod biomass in the ground layer (fresh weight) according to pitfall trap samples in birch and pine forests in 1989 and 1990.

in a line in each of two birch forests and two pine forests during the years 1989-1990. The traps were emptied once a week and the biomass of arthropods (wet weight) measured. In 1987-89 two sweepnetting lines ( 50 hits/line) were run in three birch forests to determine the abundance of arthropods on the dwarf shrubs. The sweep collected arthropods from shrubs and flying insects at a height of $0-30 \mathrm{~cm}$. Because of the considerable variance among observers, annual sweep-netting data are given in percentage of the annual biomass peak.

Arthropods living in foliage were collected using the tree-knocking method at four study sites in the Utsjoki valley (Eeva 1989). The study birches were $4-6 \mathrm{~m}$ high. A plastic blanket $(3 \times 3 \mathrm{~m})$ was spread under the tree, and arthropods were collected from the blanket after knocking the trunk once. We knocked 10-35 trees per study site during the summer. Only one sample/tree/summer was taken.

The abundance of foliage-feeding larvae was studied by measuring their faeces production with frass-collectors (area $0.5 \mathrm{~m}^{2}$ ). We had 8-10 collectors under pines (average tree height $9.0 \mathrm{~m}$ ) and birches (average height $5.7 \mathrm{~m}$ ). We present combined frass fall data from the years 1986-1991 and 1993 in this study. Data were collected at Kevo from two sites during all seven years. Collectors were emptied once a week. The dry weights (to the nearest $0.1 \mathrm{mg}$ ) of the faeces were corrected for the effect of rain using Tenow \& Larsson's (1987) formula for the frass of Neodiprion sertifer (Geoffroy) (Hymenoptera) as $\mathrm{Y}=20.75\left(1-\mathrm{e}^{-0.091 \mathrm{X}}\right)$, where $\mathrm{Y}$ is the percentage of dissolved faeces and $\mathrm{X}$ is the amount of precipitation (in $\mathrm{mm}$ ). The seasonal fluctuation of arthropod abundance is presented in 10-day periods (20 May-29 May, and so on).

\section{Results}

In pitfall samples, Araneae was the most common taxon $(89.6 \%$ of wet weight). The vast majority of the spiders trapped belonged to the Lycosidae family (cf. Koponen 1975). In both forest types spiders were most abundant in June. Coleoptera made up the major proportion of the group 'Others' ( $8.2 \%$ of wet weight). 

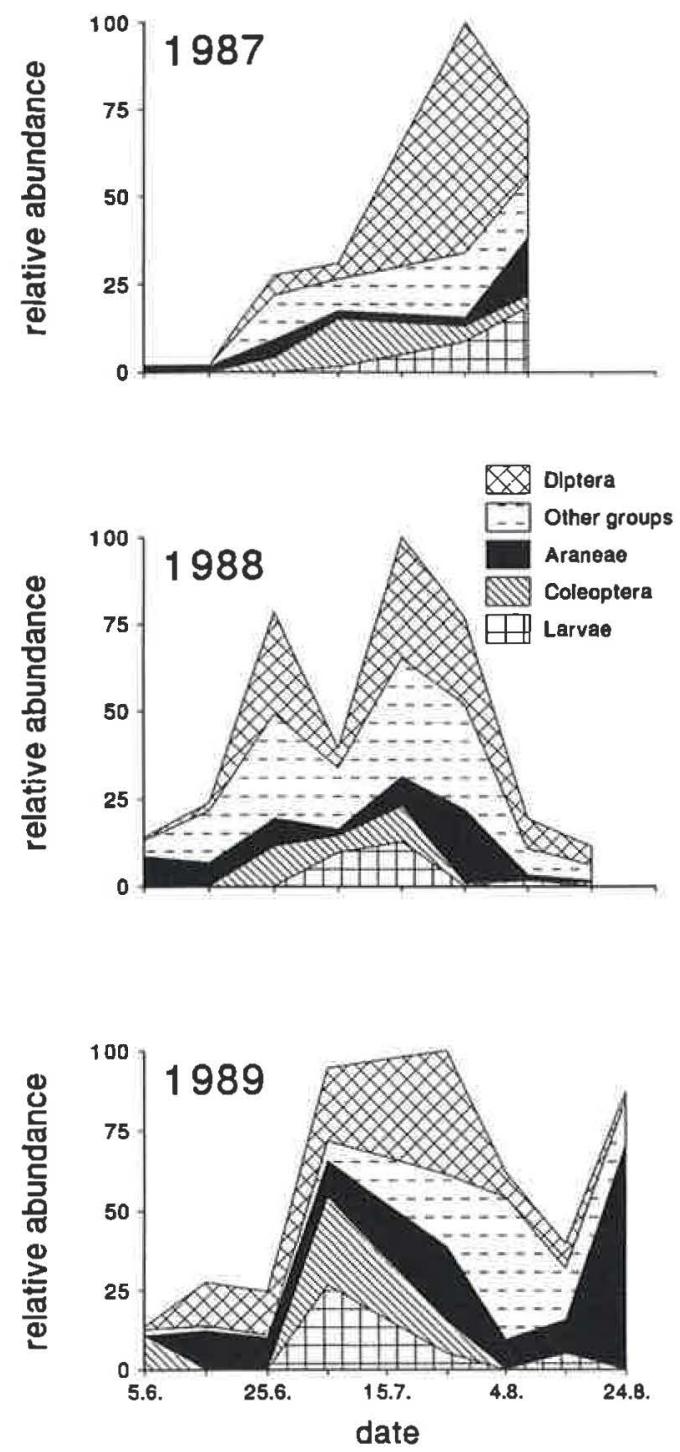

Fig. 2. Abundance (fresh weight) of arthropods collected by sweep netting expressed as percentage of the largest sample in each year in 1987-1989. This scaling was used because of the change of observers in each year. Larvae = Lepidoptera $(16 \%)$ and $\mathrm{Hy}$ menoptera (84\%) larvae. The group 'Others' includes Lepidoptera (ad.), Hymenoptera (ad.), Homoptera, Heteroptera, Odonata, Ephemeroptera and Trichoptera.

Diptera dominated the sweep-net samples (on average $32.3 \%$ of biomass, Fig. 2). The abundance of diptera increased from June to July, especially in 1987 and 1989. Variation in the size distribution of Diptera was considerable. Large and visible craneflies (Tipulidae) were
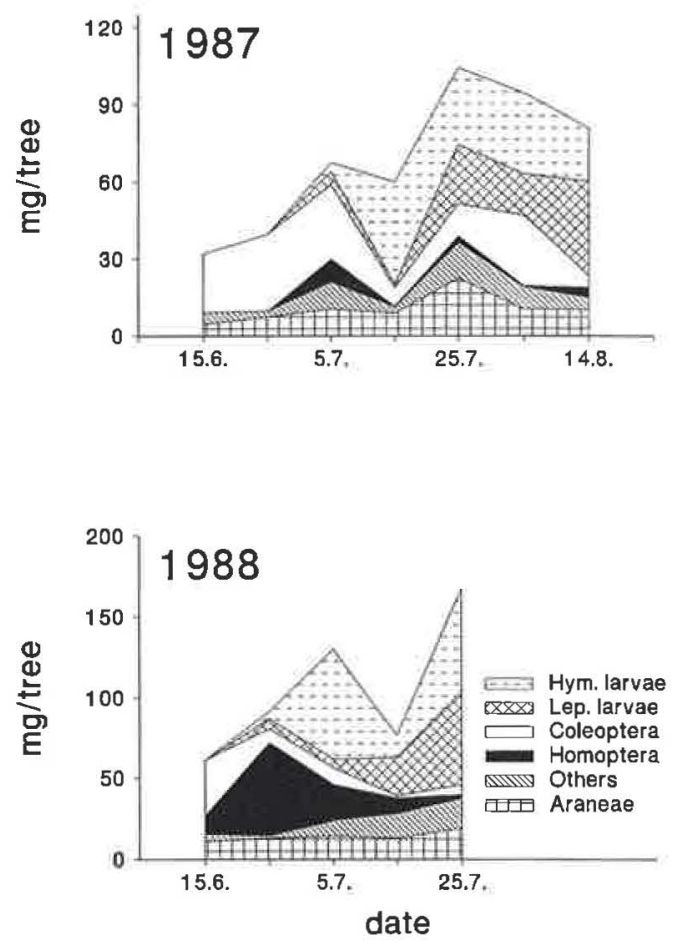

Fig. 3. Seasonal variation in biomass of selected arthropod taxa (fresh weight) on the foliage of birches measured using the tree-knocking method.

abundant in July, but the peaks were caused by the superabundant small Diptera (Simuliidae, Culicidae). The peak in the abundance of Coleoptera in sweep-netting samples occurred in the beginning of July, as it did also in the pitfall trap samples (Figs. 1, 2). Araneae (mainly Linyphiidae and Thomisidae) seemed to be most abundant in late summer on dwarf shrubs.

Coleoptera (especially Chrysomelidae) was the dominant group on the foliage of birches in the beginning of the summer (Fig. 3). In addition, Homoptera (Psyllodea and Aphidodea) were abundant in June 1988. The abundance of Araneae was constant throughout the summer on the foliage of birches. The biomass of larvae increased from June to August almost linearly (Fig. 4). In June, only hymenopteran larvae were common. The most abundant sawfly larvae were Dineura virididorsata Retzius, but Amauronematus sp. and Nematus sp. were also common. In August, lepidopteran larvae were also more abundant (the most common genera were geometrids Lycia sp. 


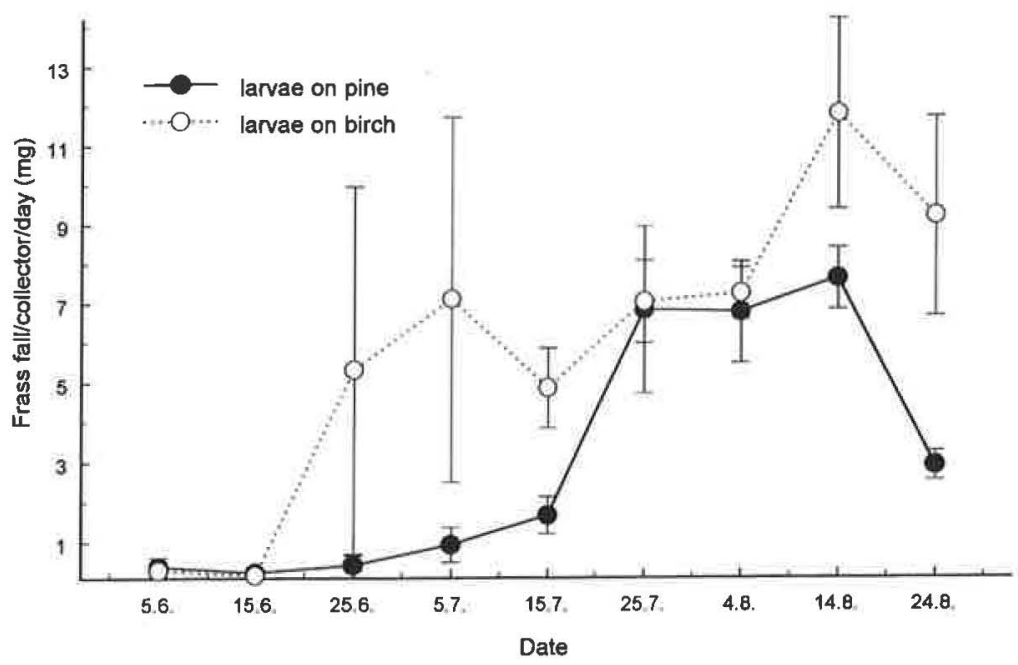

Fig. 4. Seasonal variation of frassfall (mean and standard error in ten day periods) on birches and pines. Data from 19861991 and $1993(n=7$ years). and Archiearis sp.). At the end of the summer, larvae made up more than $50 \%$ of the arthropod biomass in the tree-knocking samples (Fig. 3).

On pines, larvae were rare up to the middle of July, but their abundance increased at the end of the summer (Fig. 4). However, they were less abundant than the larvae on birches. The only frassproducers on pines were found to belong to the genera Neodiprion sp. (Symphyta: Diprionidae) and Acantholyda sp. (Symphyta: Pamphiliidae).

\section{Discussion}

Araneae, which is the most important predatory arthropod taxon in our study area, was most abundant in the beginning of the summer on the ground layer (Koponen 1975 and this study). On the foliage of trees, the abundance of spiders did not vary noticeably during the summertime. On the dwarf shrubs, the total peak in arthropod abundance occurred at the end of July every summer. This was especially due to the late peak abundance of Diptera.

On the foliage of birches, Homoptera had their peak in June (also Haukioja \& Koponen 1975). In addition, Coleoptera had their peak in the beginning of the summer (cf. Haukioja \& Koponen 1975). All in all, the total biomass peak occurs in late summer, because the larvae of many groups did not increase in numbers before mid-July (Koponen 1973, Haukioja \& Koponen 1975, cf. Tenow 1972).

We suggest that the great seasonal variation in the abundance of arthropods in different parts of the forest has considerable effects on the northern ecosystems. Wolda (1988) stated that temperature is the most important factor determining the seasonal variation of insects. Most arthropod taxa, therefore, have their peak occurrence quite late at northern latitudes. Furthermore, there are only a few groups which overwinter in stages in which they become available for predators in early summer. Vertebrate predators preying upon arthropods, such as insectivorous birds, are therefore food-limited in the early summer. By contrast, the arthropod prey have their peak abundance in late summer, and thereby gain a partial refuge at that time. This arises from the fact that predator birds are not able to fully utilize the highest peak because of the food limitation earlier in the breeding season. The minimum time required for fulfilling the breeding schedule of insectivorous passerines, c. 80 days, contributes significantly to the above pattern.

Acknowledgements. We thank Lasse Iso-Iivari, Sinikka Hanhimäki, Erkki Haukioja, Vesa Koivunen, Martti Komulainen, Seppo Neuvonen, Elina Pallas, Marja Törvi, and the staff of Research Institute for their help in various aspects of this work. David Bergen checked the language. The study was financially supported by the Emil Aaltonen Foundation and the Turku University Foundation.

\section{References}

Eeva, T. 1989:Eläinravinnon merkitys lapintiaisen (Parus cinctus) ja kirjosiepon (Ficedula hypoleuca) pesinnän ajoituksessa Inarin Lapissa (in Finnish). - Unpubl. 
M. Sc. Thesis, Dept. Biology, Univ. Turku.

Haukioja, E. \& Koponen, S. 1975: Birch herbivores and herbivory at Kevo. - In Wielgolaski, F. E. (ed.): Ecological studies. Analysis and Synthesis. Vol. 17. Fennoscandian Tundra Ecosystems. Part 2:181-188.

Kallio, P., Laine, U. \& Mäkinen, Y. 1969: Vascular flora of Inari Lapland. 1. Introduction and LycopodiaceacPolypodiaceac. - Rep. Kevo Subarctic Res. Stat. 5:152.

Koponen, S. 1973: Herbivorous invertebrates of the mountain birch at Kevo, Finnish Lapland. - Rep. Kevo Subarctic Res. Stat, 10:20-28.

- 1975: Spider populations in a subalpine birch forest. - In Wielgolaski, F, E. (ed.): Ecological studies.
Analysis and Synthesis, Vol. 17. Fennoscandian Tundra Ecosystems, Part 2:66-72.

Krebs, C. J. 1985: Ecology: the experimental analysis of distribution and abundance. 3rd ed. - Harper, New York. 800 pp.

Tenow, O. 1972: The outbreaks of Oporinia autumnata Bkh. and Operophthera spp. (Lep., Geometridae) in the Scandinavian mountain chain and northem Finland 19621968. - Zool. Bidrag Uppsala, Suppl. 2:1-107.

Tenow, O. \& Larsson, S. 1987: Consumption by needle eating insects on Scots pine in relation to season and stand age. - Holarct. Ecol. 10:249-260.

Wolda, H. 1988: Insect seasonality: Why? - Annu. Rev. Ecol. Syst. 19:1-18. 